\title{
Implications of Disruption to Natural Gas Deliverability
}

U.S. Department of Energy Award DE-FC-03NT41919

Sponsored by the

U.S. DOE Office of Electricity Delivery \& Energy Reliability

Analysis of the Ability of the Natural Gas Market to

Withstand Loss of Pipeline Capacity

\section{Summary of All Project Reports}

\author{
Submitted by: \\ Gas Technology Institute \\ 1700 South Mount Prospect Road \\ Des Plaines, Il 60018 \\ Principal Author: \\ Science Applications International Corporation (SAIC) \\ 8301 Greensboro Drive \\ McLean, Va. 22102
}

FINAL REPORT

Period of Performance:

September 2003 to September 2008 


\section{Disclaimer}

This report was prepared as an account of work sponsored by an agency of the United States Government. Neither the United States Government nor any agency thereof, nor any of their employees, makes any warranty, express or implied, or assumes any legal liability or responsibility for the accuracy, completeness, or usefulness of any information, apparatus, product, or process disclosed, or represents that its use would not infringe privately owned rights. Reference herein to any specific commercial product, process, or service by trade name, trademark, manufacturer, or otherwise does not necessarily constitute or imply its endorsement, recommendation, or favoring by the United States Government or any agency thereof. The views and opinions of authors expressed herein do not necessarily state or reflect those of the United States Government or any agency thereof. 


\begin{abstract}
This project was sponsored by Department of Energy/Office of Electricity Delivery and Energy Reliability and managed by the National Energy Technology Laboratory. The primary purpose of the project was to analyze the capability of the natural gas production, transmission and supply systems to continue to provide service in the event of a major disruption in capacity of one or more natural gas transmission pipelines. The project was specifically designed to detail the ability of natural gas market to absorb facility losses and efficiently reallocate gas supplies during a significant pipeline capacity disruption in terms that allowed federal and state agencies and interests to develop effective policies and action plans to prioritize natural gas deliveries from a regional and national perspective.
\end{abstract}

The analyses for each regional study were based on four primary considerations: (1) operating conditions (pipeline capacity, storage capacity, local production, power dispatch decision making and end user options); (2) weather; (3) magnitude and location of the disruption; and, (4) normal versus emergency situation.

The detailed information contained in the region reports as generated from this project are Unclassified Controlled Information; and as such are subject to disclosure in accordance with the Freedom of Information Act. Therefore, this report defines the regions that were analyzed and the basic methodologies and assumptions used to completing the analysis. 


\section{Acknowledgements}

The analytical components of this report with respect to the "gas disruption analyses" were prepared based on the analysis of eight market regions and two production regions and on a written report covering three market regions prepared by ICF International, formerly, the Energy and Environmental Analysis, Inc. (EEA), as a sub-contractor in this project. (In January 2007, EEA became a wholly owned subsidiary of ICF International. ICF/EEA developed the methodologies; the tools/models used to implement the methodologies, executed the model runs, consulted with natural gas industry LDC and pipeline companies in the Industry Review Process, performed the analyses and compiled the results in a period from October 2003 to September 2008. Sub-contractor SAIC prepared written reports based on the PowerPoint presentations prepared by ICF/EEA. EEA prepared one report dated December 2003. The analytical components of all "gas disruption analyses" reports, including this Summary Report, are based on the analysis in the ICF/EEA products. In performing these functions in this project, ICF/EEA used the methodology, and the tools/models that EEA had previously developed and used as the contractor responsible for the original Northeast Study funded by the Interstate Natural Gas Association of America (INGAA) and the American Gas Association (AGA). The models and methodology developed and used by ICF/EEA remain the exclusive property and are under the control of ICF/EEA. This report has been edited for content by the National Energy Technology Laboratory. 


\section{$\underline{\text { Table of Contents }}$}

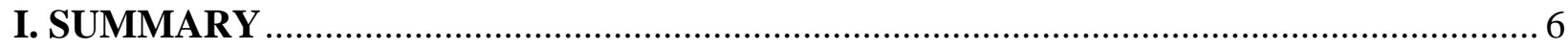

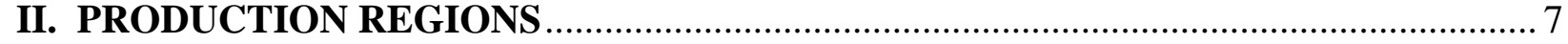

A. Rocky Mountain Production Region ............................................................................ 7

B. Gulf Coast Production Region

C. Northeast Region..........................................................................8

D. California and Western States Region...................................................9

E. East - North Central Region...............................................................10

\section{ATTACHMENTS:}

Attachment 1

Attachment 2 


\section{Implications of Disruption to Natural Gas Deliverability}

\section{Summary}

This Summary Report is part of a project sponsored by Department of Energy/Office of Electricity Delivery and Energy Reliability to analyze the capability of the natural gas markets in the different regions of the country to continue to provide service in the event of a major disruption in capacity of one or more natural gas pipelines providing gas to the region. The project was specifically designed to detail the ability of natural gas market to absorb facility losses and efficiently reallocate gas supplies during a significant pipeline capacity disruption in terms that allowed federal and state agencies and interests to develop effective policies and action plans to prioritize natural gas deliveries from a regional and national perspective.

Recent events, and corresponding federal government policy concerns, have brought to the fore the interrelationship of the policy areas of reliability and security relative to natural gas. Ensuring the reliability and security of the interstate natural gas transmission system is important because the system is relied on as the nearly exclusive means to deliver the nation's natural gas supply from production regions to delivery points throughout the country for transfer and ultimate use in homes, industry and electric generators. Natural gas is an important component to the well-being of U.S. citizens and the nation's economy. Government policymakers, at both the federal and state levels, working closely with the natural gas industry, must have an analytical basis to help in performing their reliability and security responsibilities relative to natural gas service. While an event causing a disruption could kill or injure people at the site, the primary large-scale adverse consequence that must be avoided relative to a major natural gas capacity disruption is the interruption of natural gas service in the region for an extended period, and the residual consequences to the well-being of citizens and the economy.

The detailed information with respect to each regional analysis is contained in the region reports. This report defines the regions that were analyzed and the basic methodologies and assumptions used to completing the analysis.

The analyses for each region are based on four primary considerations: (1) operating conditions (pipeline capacity, storage capacity, local production, power dispatch decision making and end user options); (2) weather; (3) magnitude and location of the disruption; and, (4) normal versus emergency situation. The results are stated as a percentage under two scenarios:

1. "Market Solution" - Market functions on its own Shows how much capacity could be disrupted and the market will continue to sufficiently provide gas to all consumers willing to buy it regardless of price.

2. "Essential Human Needs Only" - Emergency actions needed Shows how much additional capacity could be disrupted and service would still be provided to "essential human needs" customers (for example, high-priority customers, such as home heating, as determined under state emergency curtailment plans). It assumes $100 \%$ of power load is shut off.

The results also show the benefits if downstream markets also impose curtailment. 
The primary operating concern in the natural gas business is avoiding a "system re-light" which is costly, time consuming and potentially dangerous. The "essential human needs" percentage identifies the capacity loss that the market can withstand before this critical threshold is crossed. The potential loss of natural gas service in the event of a major pipeline disruption during peak winter months was examined as the scenario with the highest potential impact.

\section{Production Regions:}

\section{A. Rocky Mountain Production Region}

The Rocky Mountain Production Region consists of New Mexico, Colorado, Utah, Wyoming and Montana. This study analyzed the impacts of a major pipeline capacity disruption relative to the capability of the markets to continue to provide service within the respective regions and examined the capability of the market to continue service within the Rocky Mountain Region and the potential impacts on the export markets outside of the region, and identified the potential impacts on consumers if key facilities and points on the system are disrupted.

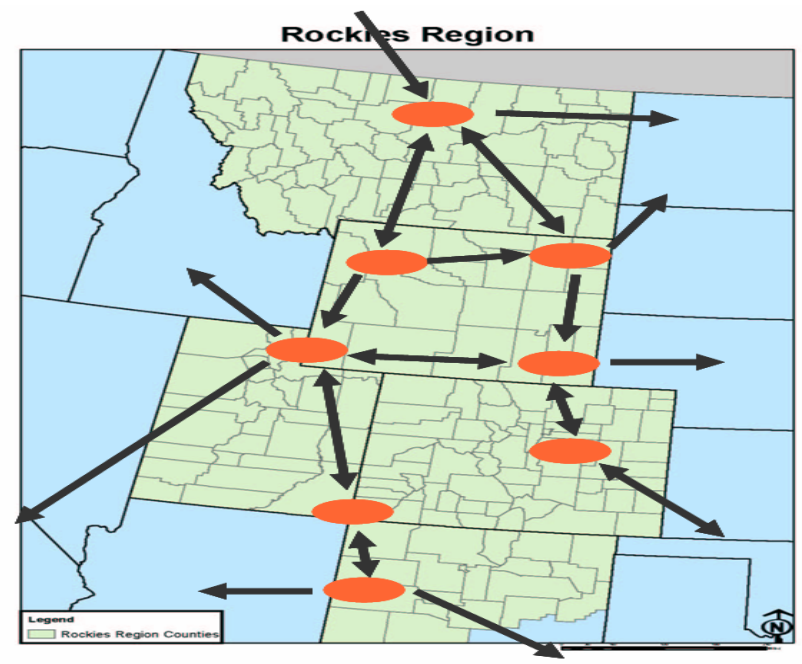

This report analyzed 22 different pipelines, 60 interconnects, three major LDCs, 15 processing plants responsible for 60 percent of the processing in the region ${ }^{1}$, one hub, the Cheyenne Hub, and 3 high volume storage fields. Part of the study selectively focused on the top 24 facilities/critical infrastructure and operational points within the system.

\section{B. Gulf Coast Production Region}

The Gulf Coast Production Region consists of Texas, Oklahoma, Arkansas, Louisiana, and Mississippi. This study, in addition to examining the capability of the market to continue service within the Gulf Coast Region, also examined the potential impacts on the export markets outside of the region, and identified the potential impacts on consumers if critical facilities and points on the system are disrupted, including hurricane scenarios.

\footnotetext{
${ }^{1}$ Approximately 100 other small plants process the remaining 40 percent.
} 


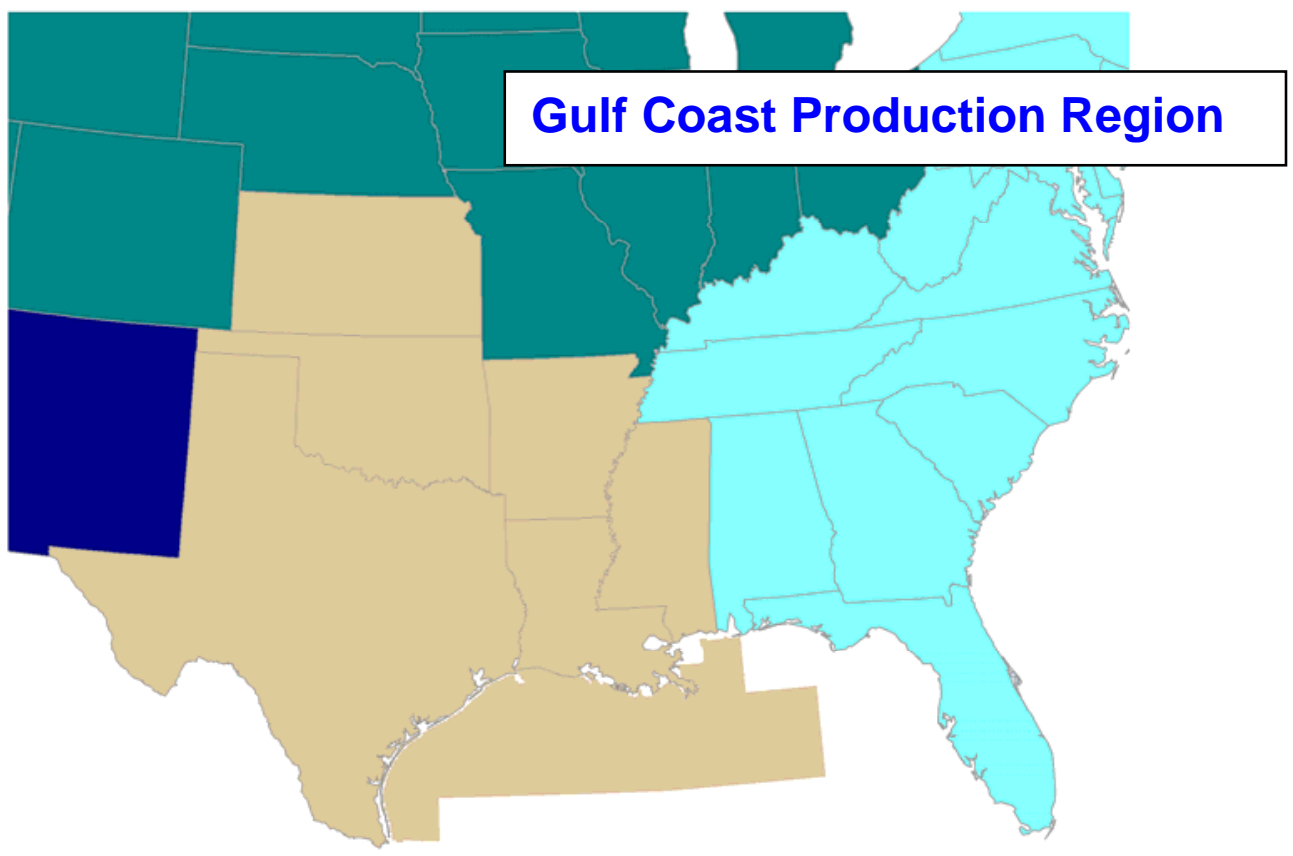

\section{Northeast Region}

The Northeast Region consists of New England, New York City, New Jersey, Eastern Pennsylvania and the BaltimoreWashington, DC area. This analysis considered two scenarios in the event of a major pipeline disruption: (1) The ability of the market, without regulatory intervention (such as emergency curtailment), to absorb and reallocate gas within the area to meet "full daily load" - to provide gas to all customers who are willing to buy it irrespective of cost (“Market Solution”); and, (2) In the event state imposed emergency curtailment plans are implemented, the market's capability to provide service to meet the area's "essential human needs only"

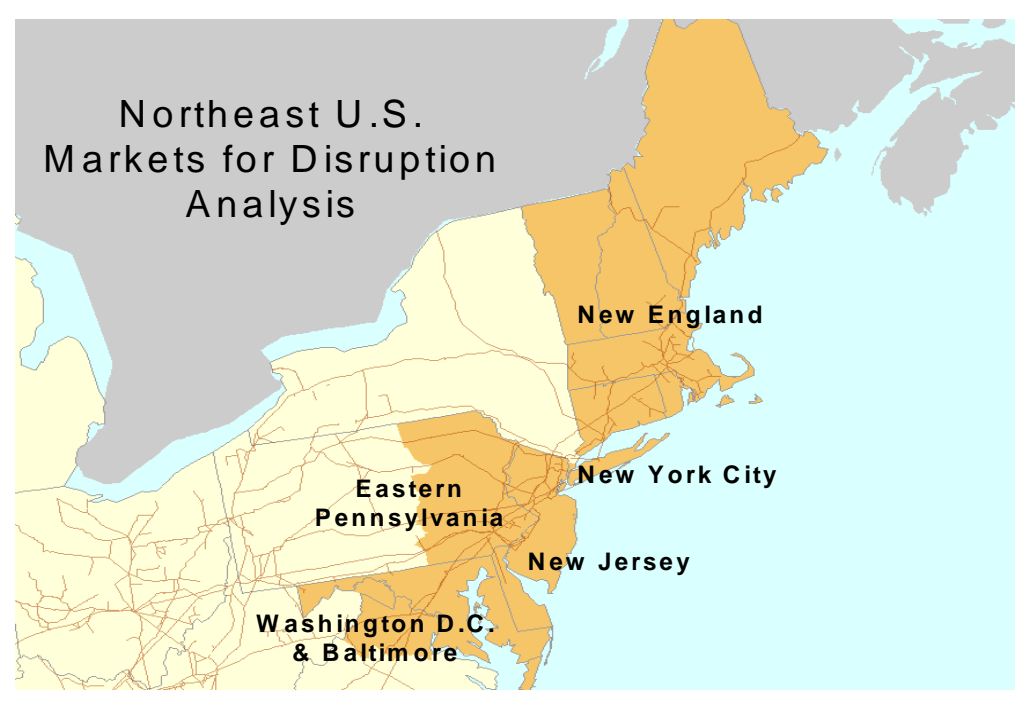
requirements, essentially barring use of natural gas for electric generation and industrial uses in order for the LDCs to serve higher priority gas customers, such as households. The analyses were performed assuming different seasons, weather temperatures, fuel switching capabilities, and optimal use of peak shaving and storage facilities in the region. The analysis assumed a 30-day pipeline capacity outage.

\section{California and Western States Region}

This region consists of California, Arizona, Nevada and Idaho. The analysis considered two scenarios in the event of a major pipeline disruption: (1) The ability of the market, without regulatory intervention (such as emergency curtailment), to absorb and reallocate gas within the area to meet "full daily load" - - to provide gas to all customers who are willing to buy it irrespective of cost ("Market Solution"); and, (2) In the event state 
imposed emergency curtailment plans are implemented, the market's capability to provide service to meet the area's “essential human needs only” requirements, essentially barring use of natural gas for electric generation and industrial uses in order to serve higher priority customers, such as households. The analyses were performed assuming different weather temperatures, high, normal and low use of hydro to generate electricity, fuel switching capabilities, and optimal use of peak shaving and storage facilities in the region.

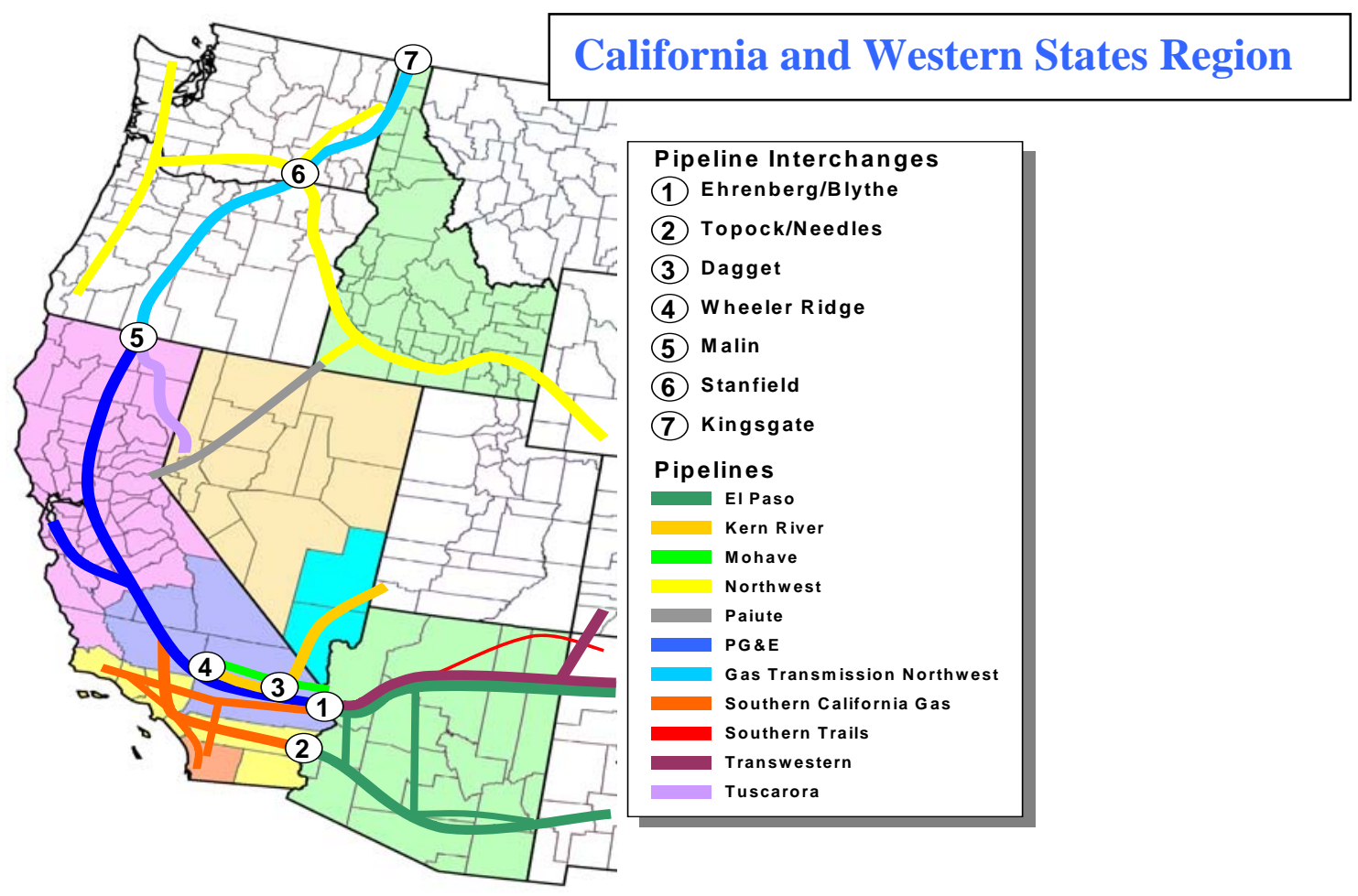

\section{E. East - North Central Region}

The East-North Central Region consists of a twelve state area, divided into five regions comprising the East - North Central States: (1) Inland Northeast (New York State and Western Pennsylvania); (2) Ohio Valley (Ohio, West Virginia, Kentucky and Tennessee); (3) Michigan; (4) Midwest (Illinois and Indiana); and, (5) Central (Missouri, Iowa, Nebraska and South Dakota).

The analysis considered two scenarios in the event of a major pipeline disruption: (1) The ability of the market, without regulatory intervention (such as emergency curtailment), to absorb and reallocate gas within the area to meet "full daily load" - - to provide gas to all customers who are willing to buy it irrespective of cost ("Market Solution"); and, (2) In the event state imposed emergency curtailment plans are implemented, the market's capability to provide service to meet the area's “essential human needs only” requirements, essentially barring use of natural gas for electric generation and industrial uses in order for the LDCs to serve higher priority gas customers, such as households. The analyses were performed assuming different seasons, weather temperatures, fuel switching capabilities, and optimal use of peak shaving and storage facilities in the region. The analysis assumed a 30-day pipeline capacity outage. 


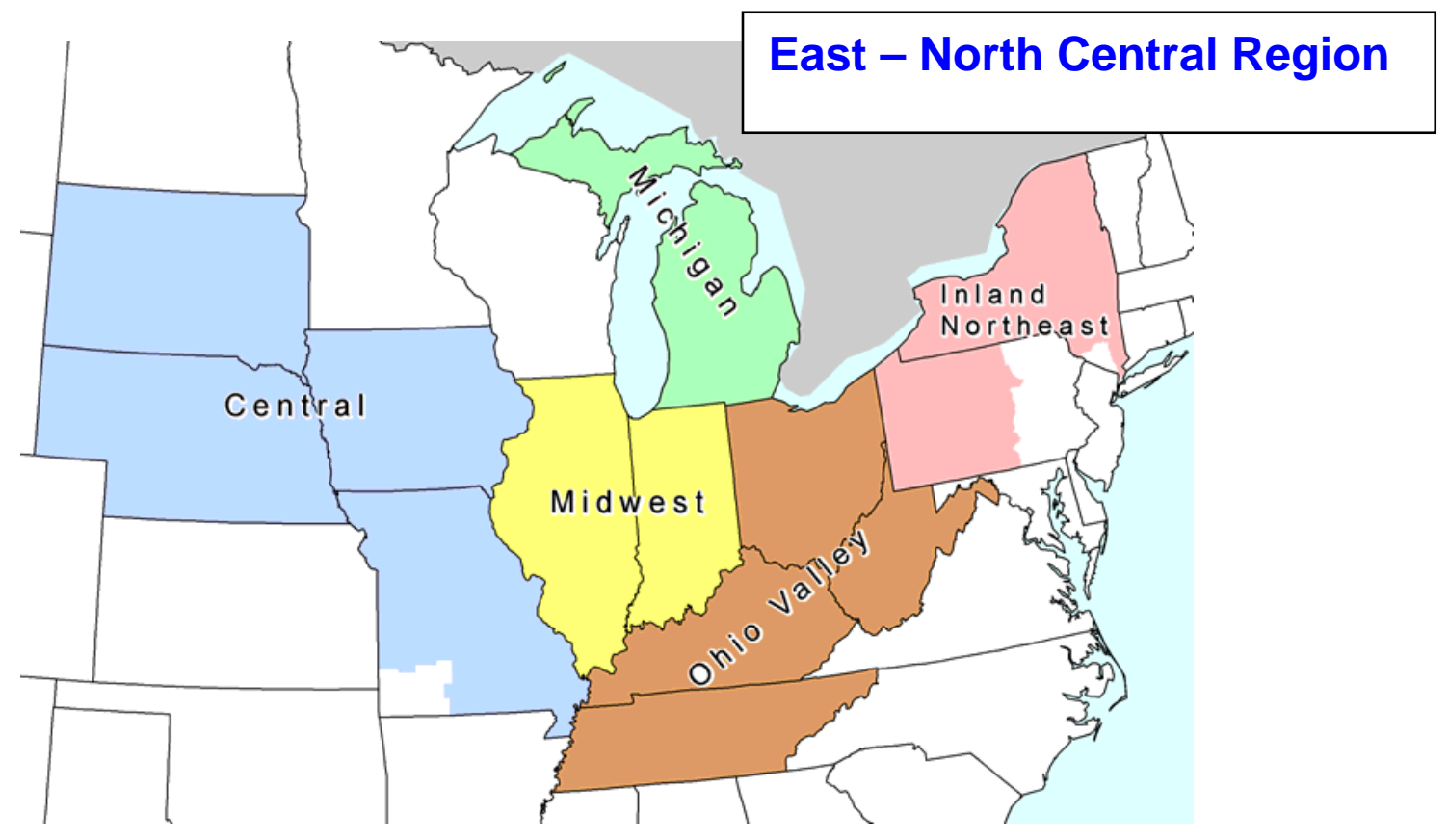




\section{ATTACHMENT 1}

\section{Operation of the Interstate Natural Gas Pipeline System}

Under FERC open access regulations, gas is purchased by the end user - - a Local Distribution Company (LDC), industrial user of gas, commercial business or electric generator - - directly from producers, or through middle-men brokers and marketers. The interstate natural gas pipeline companies, operating over 300,000 miles of pipelines throughout the country, serve as transporters of the gas. The pipelines do not own the gas, but rather transport the gas for fee from "receipt points" in the production regions, generally Texas, Louisiana, Oklahoma and the Rocky Mountain Region, to a designated "delivery point" for the end user.

When the purchasers (called "shippers" in FERC terminology) purchase gas, they must also purchase capacity from an interstate pipeline to transport the gas to its destination. In many instances, the industrial users, commercial businesses and electric generators purchase the gas from LDCs, and only the LDC needs to purchase capacity from the pipeline. LDCs sell capacity on their distribution pipelines to transport gas within their service territory to homeowners, industrial users, commercial businesses and electric generators. In some instances, purchasers such as electric generators and large industrialusers purchase pipeline capacity to take delivery of the gas directly off of the interstate pipeline for use at their facilities near the pipeline without using the LDC's system.

The purchase of the gas itself and the capacity to transport it can be either under a higher priced, "firm" contract or a lower-priced, "interruptible" contract depending on the level of assurance needed or risk the purchaser is willing to take. "Firm" contracts offer the highest level of assurance to the purchaser that the gas will be delivered. Only an extreme event such as a natural disaster, or implementation of a State - imposed "curtailment" plan should prevent delivery of firm service gas. "Interruptible” contracts recognize that service can be bumped in tight, high-priced market conditions, such as cold weather, when "firm" service obligations take precedence for all or most of the capacity on a pipeline, or the gas itself.

The interstate pipeline and LDC infrastructure is built to satisfy peak demand - - the coldest months and days. Significant pipeline disruption is most likely to pose problems during peak winter months. In the event of a major pipeline disruption, the amount of capacity outage that can be accommodated by the market through "economic reallocation" of remaining supplies depends on the time of year, weather, location of the outage, amount of fuel switching capability, and storage and peak shaving capacity, among other factors. 


\section{ATTACHMENT 2}

\section{Methodology:}

The analytical components, charts and pictures contained in this report are based on the analysis and information provided by the Energy and Environmental Analysis (EEA). The Regional Disruption Analyses for the five regions are based on three primary components (Each factor is discussed generally below, and more specifically under the discussion of the individual region):

(1) Pipeline Capacity: The physical capabilities of the pipeline capacity and system components serving the market, including storage;

(2) Weather: The different seasons and the severity of the temperature; and,

(3) Normal vs. Emergency Situation: Whether the system is operating under normal business conditions or under a state approved emergency curtailment.

The study is based on a regional perspective - - examining the ability of the regional natural gas market to withstand disruption of interstate pipeline capacity and continue to provide service to the region. It does not examine localized loss of service - - the loss of service that an individual LDC might incur - - which must be examined separately.

The methodology assumes a sustained 30-day pipeline capacity outage, a pipeline flow response to changing market conditions, including fuel switching and conservation, and alternative paths to obtaining gas supply. With respect to peak-shaving, it assumes that $60 \%$ of observed utilization in each market is available in January.

Storage: Natural gas storage is an important source of supply for LDCs during adverse weather conditions. Because of the importance of weather, the analyses assess the impacts of a major pipeline disruption that would result under four weather scenarios in the winter - when peak demand will occur - - using January as the test month. The weather scenarios are based on historic census heating-degree data for the market area. Specifically, for the winter the analyses use the $85^{\text {th }}, 75^{\text {th }}, 50^{\text {th }}$ (normal) and $25^{\text {th }}$ percentile historically coldest January months (the coldest "heating-degree” data).

The methodology provides analysis under two operational scenarios to show the capability of the market to provide full or curtailed gas service in the event of a capacity disruption. The capability is stated in terms of percentages. The percentages indicate the maximum percentage of the pipeline capacity bringing gas to the region that can be disrupted (in the season/weather examined) before the market has an insufficient level of gas to meet either full or curtailed service needs. Two sets of percentages are provided:

- "Full Daily Load" (Market Solution): This scenario assumes that, in the event of a disruption, the market will provide an "economic reallocation” among end-user customers of the gas service that would remain available in the region. It captures all the market mechanisms that would interact to absorb an outage, including fuel switching capability and use of peak shaving and gas from available storage facilities. The analysis generates a percentage to indicate/represent the maximum level of pipeline capacity that could be disrupted yet allow the market to satisfy the load needs of the remaining customers who have not elected, or been able, to switch to an alternate energy source and are still willing to - - or must - - buy natural gas, irrespective of its price.

- "Essential Human Needs Only": This scenario assumes that, in the event of a disruption, the impacted states have implemented emergency curtailments plans. 
These State-approved curtailments on LDCs impose conservation or temporary closure of gas-dependent industrial and commercial facilities, as well as gas-fired power generation served by LDCs. ${ }^{2}$ The analysis generates a percentage to indicate/represent the maximum level of pipeline capacity that could be disrupted if the market is required to serve only the "essential human needs" customers - high-priority customers, as determined under state emergency curtailment plans, such as home heating. Because this scenario reduces the customer base to only "essential human needs" customers, the percentage (capacity serving the region that could be lost) will be higher than that for "full daily load".

The percentages developed from these methodologies provide estimates for different combinations of winter weather temperatures, the maximum percent of pipeline capacity that can be taken out of service in the region and continue to provide gas service to customers under two scenarios previously defined in this report (i.e. Market Solution and Essential Human Needs Only).

\footnotetext{
${ }^{2}$ The analysis assumed 100 percent of the gas-fired electric generation would be curtailed irrespective of whether the generator received the gas from an LDC, or directly from the interstate pipeline.
} 